\title{
The Use of N-Terminal-Pro-BNP in Preterm Infants
}

\author{
Afif EL-Khuffash ${ }^{1,2}$ and Eleanor Molloy ${ }^{2,3,4}$ \\ ${ }^{1}$ Department of Neonatology, Hospital for Sick Children, Toronto, ON, Canada M5G 1X8 \\ ${ }^{2}$ Department of Postgraduate Research, School of Medicine and Medical Sciences, University College Dublin, Dublin 4, Ireland \\ ${ }^{3}$ Department of Neonatology, National Maternity Hospital, Dublin 2, Ireland \\ ${ }^{4}$ Department of Neonatology, Lady's Children's Hospital, Crumlin, Dublin 12, Ireland
}

Correspondence should be addressed to Afif EL-Khuffash, afif_faisal@hotmail.com

Received 9 September 2009; Accepted 16 November 2009

Recommended by Peter Oishi

The use of natriuretic peptides in the neonatal population is emerging. B-type Natriuretic Peptide (BNP) and N-terminal-Pro-BNP (NTpBNP) are used in the adult population to assess myocardial function and volume loading. Their role in prognosis following cardiac surgery has also been identified. In preterm infants NTpBNP is becoming increasingly recognised as a potential screening tool for patent ductus arteriosus (PDA), and a marker for myocardial performance. In addition, NTpBNP may provide prognostic information in preterm infants and term infants with congenital diaphragmatic hernia $(\mathrm{CDH})$. In this paper, the role of NTpBNP in the preterm population will be discussed.

Copyright ( 2009 A. EL-Khuffash and E. Molloy. This is an open access article distributed under the Creative Commons Attribution License, which permits unrestricted use, distribution, and reproduction in any medium, provided the original work is properly cited.

\section{Introduction}

B-type Natriuretic Peptide (BNP) is a 32-amino acid ring structure coded by a sequence on chromosome 1 . BNP acts on a cyclic guanosine monophosphate (cGMP) coupled receptor via a transmembrane domain [1]. The ventricles of the heart are the main site of BNP synthesis and release in response to volume loading, pressure loading, and ventricular stress. BNP causes diuresis, natriuresis, arterial and venous vasodilatation, and antagonises the reninangiotensin system. The net effect is a reduction of intravascular volume, ventricular preload and afterload. The ring structure must remain intact to ensure receptor binding to natriuretic peptide receptors $\mathrm{A}$ and $\mathrm{B}(\mathrm{NPR}-\mathrm{A} / \mathrm{B})$. BNP is excreted following cleavage by membrane bound neutral peptidase found in the kidneys and vascular tree. NPR-C also clears it from the blood by binding, endocytosis, and lysosomal degradation [2]. N-terminal-Pro-BNP (NTpBNP) is the inactive by-product of BNP resulting from the cleavage of the parent peptide Pro-BNP. Both are released into the circulation but no function has been associated with NTpBNP. BNP has a short half-life of 20 minutes and is unstable at room temperature. NTpBNP has a longer halflife of compared to 60 to 120 and is stable under a range of storage conditions. There are multiple kits available for
BNP measurements. This has led to discrepancies in cut off levels across studies used for assessing BNPs prognostic and haemodynamic assign properties. On the other hand, available kits used for NTpBNP measurement are limited in number. This may allow more comparisons to be made across studies, thereby rendering it more suitable than BNP for routine clinical monitoring [3].

\section{Clinical Role of Natriuretic Peptides}

BNP and NTpBNP are good screening tools, detecting chronic ventricular dysfunction in adults, with sensitivities and specificities surpassing clinical and radiological methods [4]. BNP and NTpBNP are useful in the diagnosis of congestive heart failure in dyspnoeic patients presenting to the emergency department [5]. In addition, these markers facilitate the screening, treatment response, and prognosis of asymptomatic patients with subclinical Left Ventricular dysfunction [6-8].

BNP and NTpBNP levels are elevated in children with heart disease causing ventricular pressure and volume loading $[9,10]$. In addition, plasma BNP correlates closely to shunt volume in left-to-right cardiac lesions, increasing with decreasing left ventricular ejection fraction, and positively 
correlating with increasing right ventricular systolic pressures [11]. The levels can also reflect functional capacity in children with congestive heart failure [9]. In children with dilated cardiomyopathy NTpBNP is a good marker for persistent left ventricular dysfunction with levels normalising in children whose echocardiograms recover [12]. Among infants with respiratory distress, plasma NTpBNP measurement can differentiate between acute heart failure and lung disease and can be used to monitor response to treatment [13]. Elevated preoperative NTpBNP in children undergoing open heart surgery is linked with complicated postoperative outcome [14]. NTpBNP is used preoperatively to predict the development of postoperative low cardiac output syndrome (LCOS) [15]. BNP levels tend to be higher in children receiving long-term immunosuppressive treatment post liver transplant compared to healthy controls despite the lack of echocardiographic evidence of cardiac compromise suggesting that BNP levels may identify patients with early cardiac damage [16].

Limited data have demonstrated the potential benefit of these peptides as markers of cyanotic and obstructive lesions. Cowley et al. demonstrated a significant, correlation between left ventricle to aorta gradient and BNP levels [17]. NTpBNP has also been used to monitor response to valve replacement in patients with aortic stenosis [18]. In a recent study, Hopkins et al. found higher levels of NTpBNP in 10 adult patients with cyanotic heart disease (including Eisenmenger's syndrome) despite the lack of ventricular pressure loading [19].

\section{Application of NTpBNP in Neonates}

BNP and NTpBNP levels surge at birth to reach a plateau on days 3 to 4 , followed by a steady fall to reach a constant level in infancy [20]. This surge is probably multifactorial but may be due to the loss of the placental low pressure system and exposure to the initially suprasystemic pulmonary pressures subjecting the ventricle to greater volume and pressure loading. Furthermore, the placenta plays a role in clearance of NPs and loss of this clearance system contributes to the high level [21]. This surge in BNP levels at birth may play a regulatory role in the haemodynamic changes associated with transition to extra-uterine life. Renal maturation, a rise in systemic vascular resistance and a fall of pulmonary pressures explain the subsequent fall in peptide levels.

There is a paucity of normative values of NTpBNP in neonates (Table 1). Reference ranges quoted in the literature vary according to the timing of the test, the kits used, and the population investigated [22]. Most quoted reference ranges are for term healthy neonates and therefore do not represent the intensive care population. NTpBNP is not thought to cross the placenta and therefore any variation in neonates must be explained intrinsically [23].

\section{Influence of Antenatal and Postnatal Events on NTpBNP Levels in Preterm Infants}

The use of NTpBNP in assessing the haemodynamic status of preterm infants is gaining interest. NTpBNP is released in equimolar amounts to BNP from the myocardium. Its levels however are higher and remain in the blood stream for longer due to differing half-life and clearance [24]. Levels of NTpBNP in the early preterm period were assessed in a study of 80 preterm infants with a median gestation of 28 [IQR 26.1-29.5] weeks and median birth weight of 1.06 [IQR $0.87-1.21] \mathrm{kg}$. At 12 hours of life all infants had a PDA with low velocity left to right shunting. The median NTpBNP value for the cohort was $1273 \mathrm{pmol} / \mathrm{L}$ with an interquartile range (IQR) of 664-2798 pmol/L and a range of 98-10 $700 \mathrm{pmol} / \mathrm{L}$. The influence of antenatal and postnatal factors on NTpBNP levels is illustrated in Table 2. Infants with RDS had significantly higher NTpBNP values compared to controls [25]. When adjusted for RDS, gestation and birth weight had no impact on NTpBNP. The premature neonatal heart is distinguished from that of older infants by several unique characteristics. The neonatal myocardium has a higher water concentration and a greater proportion of "stiff" collagen resulting in a noncompliant ventricle and diastolic dysfunction resulting in relatively poor ventricular filling [26]. The preterm myocardium cannot therefore respond to stress caused by the rise in afterload following the loss of the low pressure system of the placenta. This problem is further compounded by any potential stressors such as hypoxia, anaemia and, mechanical ventilation which reduces venous return and cause pressure on the myocardium preventing effective contraction [27]. This may explain the higher values of NTpBNP seen in preterm infants compared to term infants.

At 12 hours of life, there is a significant negative correlation between NTpBNP and echocardiographic markers of left ventricular function including mean velocity of circumferential fibre shortening (mVcfs) $(r=-0.32, P=.02)$, and shortening fraction $(r=-0.26, P=.03)$. Interestingly, there is no correlation between NTpBNP and left atrial to aortic root ratio (LA : Ao) or the diameter the PDA at 12 hours of life $(r=-0.14, P=.24)$. Echocardiographic assessment of the effect of ductal shunting on the systemic and pulmonary circulations suggests that shunting across the PDA is not significant at this early stage due to the relatively high pulmonary vascular resistance [28].

NTpBNP levels were assessed in the same population of infants at 48 hours of age [29]. Forty five infants developed a PDA compared to 35 infants who closed their ducts spontaneously beyond 48 hours. Infants with a PDA had a significantly higher NTpBNP levels compared to controls (6059 versus $740 \mathrm{pmol} / \mathrm{L}, P<.001)$. There is a significant strong correlation between NTpBNP and LA : Ao $(r=$ $0.49, P \leq .001)$, PDA diameter $(r=0.54, P=.001)$. NTpBNP provided information regarding the effects of the PDA on pulmonary overcirculation, represented by a positive correlation between levels and a rising left ventricular output (LVO) $(r=0.31, P=.006)$ and an increasing mitral valve inflow signal $(r=0.34, P=.007)$ assessed by echocardiography. In addition, NTpBNP provides information regarding systemic hypoperfusion. This was represented by a negative correlation with descending aortic end diastolic velocity $(r=$ $-0.58, P=.001)$, and celiac artery blood flow $(r=-0.41$, $P=.001)$. A Receiver operating characteristics curve (ROC) 
TABLE 1: Reference ranges for NTpBNP.

\begin{tabular}{|c|c|c|c|c|}
\hline Study & $\mathrm{N}$ & Age range/source & Kit & NTpBNP levels \\
\hline \multirow[t]{2}{*}{ Mir et al. [20] } & 153 & Day 1 & Biomedica & Mean: $641 \mathrm{pmol} / \mathrm{L}$ \\
\hline & & Venous/cord & & Range: 254-1272 \\
\hline \multirow[t]{2}{*}{ Mir et al. [20] } & 153 & Day 3 & Biomedica & Mean: 246 \\
\hline & & Venous/cord & & Range: $110-430 \mathrm{pmol} / \mathrm{L}$ \\
\hline \multirow[t]{2}{*}{ Nir et al. [22] } & 43 & 0-2 days & Elecsys & Median: $376 \mathrm{pmol} / \mathrm{L}$ \\
\hline & & & $1010 / 2010$ & Range: $30-1560 \mathrm{pmol} / \mathrm{L}$ \\
\hline \multirow[t]{2}{*}{ Bar-Oz et al. [23] } & 122 & Day 1 & Elecsys & Mean: $68 \mathrm{pmol} / \mathrm{L}$ \\
\hline & & Cord blood & $1010 / 2010$ & SD: $41 \mathrm{pmol} / \mathrm{L}$ \\
\hline \multirow[t]{2}{*}{ Bar-Oz et al. [23] } & 33 & Day 1 & Elecsys & Mean: $359 \mathrm{pmol} / \mathrm{L}$ \\
\hline & & Plasma & $1010 / 2010$ & $\mathrm{SD}: 210 \mathrm{pmol} / \mathrm{L}$ \\
\hline \multirow[t]{2}{*}{ Schwachtgen et al. [30] } & 62 & Day 1 & ECLIA & Mean: $97 \mathrm{pmol} / \mathrm{L}$ \\
\hline & & Cord blood & Roche & Range: $33-306 \mathrm{pmol} / \mathrm{L}$ \\
\hline \multirow[t]{2}{*}{ Hammerer-Lercher et al. [31] } & 42 & Day 1 & Elecsys & Mean: $65 \mathrm{pmol} / \mathrm{L}$ \\
\hline & & Cord blood & 1010 & IQR: 49-98 pmol/L \\
\hline \multirow[t]{2}{*}{ Bakker et al. [32] } & 67 & $32-42 w k$ & Elecsys & Mean: $79.5 \mathrm{pmol} / \mathrm{L}$ \\
\hline & & Cord blood & 2010 & SD: $42.9 \mathrm{pmol} / \mathrm{L}$ \\
\hline \multirow[t]{2}{*}{ Rauh and Koch [33] } & 13 & $<1$ month & Elecsys & Range: $132-913$ pmol/L \\
\hline & & Plasma & & \\
\hline \multirow[t]{2}{*}{ Soldin et al. [34] } & $400^{7}$ & $<31$ Days & Dade RxL & 97.5th percentile: $3352 \mathrm{pmol} / \mathrm{L}$ \\
\hline & & Plasma & Dimension & \\
\hline \multirow[t]{2}{*}{ Soldin et al. [34] } & 53 우 & $<31$ days & Dade RxL & 97.5th percentile: $4940 \mathrm{pmol} / \mathrm{L}$ \\
\hline & & Plasma & Dimension & \\
\hline \multirow[t]{2}{*}{ EL-Khuffash et al. [25] } & 80 & 12 hours of life & Elecsys & Mean: $1273 \mathrm{pmol} / \mathrm{L}$ \\
\hline & & $<1500$ grams & 2010 & IQR: 664-2798 range: $94-10700$ \\
\hline
\end{tabular}

TABLE 2: Influence of antenatal and factors on NTpBNP levels at 12 hours (Mann Whitney U test was used to compare medians).

\begin{tabular}{lccc}
\hline Grouping variable & Group & \multicolumn{2}{c}{ NTpBNP (pmol/L) } \\
& & Median & $P$-value \\
\hline Sex & Boy & 1273 & .32 \\
Chorioamnionitis & Nirl & 1454 & \\
& Yes & 1199 & .07 \\
Steroids & None & 1586 & .42 \\
& Partial & 840 & \\
& Full & 1462 & \\
Delivery & SVD & 1275 & .60 \\
\multirow{2}{*}{ Inotrope use } & CS & 1222 & \\
& No & 1368 & .83 \\
RDS & Yes & 1269 & \\
& No & 815 & .04 \\
\hline
\end{tabular}

was constructed to evaluate the bioassays' detection of a PDA confirmed by echocardiography, with an area under the curve (AUC) of 0.88 (95\%CI 0.79-0.96) for NTpBNP. At $4000 \mathrm{pmol} / \mathrm{L}$, NTpBNP had a sensitivity of 70\% and a specificity of $89 \%$ for the presence of a PDA [35].

The association between NTpBNP and PDA levels was replicated in three other studies (Table 3 ). The cut-off levels for the detection of a PDA vary by 2- to 3-fold amongst the studies (Table 3 ). This may be due to the different populations studied and the differing definition of a haemodynamically significant PDA across the studies. In the three other studies, no echocardiographic assessments were carried out to assess systemic hypoperfusion and pulmonary circulation [36-38]. They relied solely on ductal diameter and LA : Ao ratio. These markers in isolation do not give an accurate assessment of the degree of ductal steal and pulmonary over circulations. Therefore, the use of a lower threshold may over diagnose a significant PDA [28, 29]. Nuntnarumit et al. found a stronger correlation with LA : Ao $(r=0.77, P=.001)$. The lack of effect of gestation and birth weight on NTpBNP levels were also demonstrated [36]. Interestingly, Farombi-Oghuvbu et al. found a weak negative correlation between gestational age and NTpBNP levels on day $1\left(r^{2}=0.16, P=.02\right)$. The lack of influence of antenatal and postnatal factors illustrated in Table 2 was replicated in their study [37]. They showed a lack of association between NTpBNP levels and prolonged rupture of membranes, the use of inotropes, and early sepsis. They did find however that there was a weak association between gestational age and NTpBNP with the levels being higher in more premature infants $(\beta=-0.495, P=.013)$.

NTpBNP may have a role in monitoring treatment response. In our population, following successful PDA treatment, NTpBNP levels fell significantly to levels similar to controls (from 6059 to $998 \mathrm{pmol} / \mathrm{L}, P<.001$ ). In the 


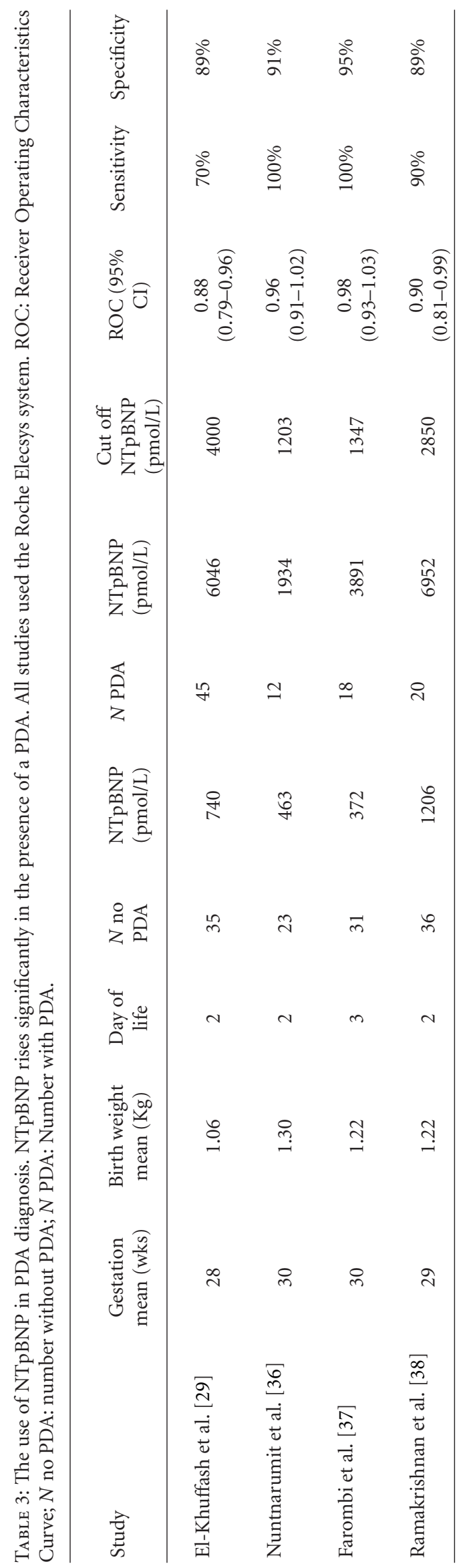


control group NTpBNP levels decreased significantly from $740 \mathrm{pmol} / \mathrm{L}$ at 48 hours to $272 \mathrm{pmol} / \mathrm{L}$ on Day 7 . Nuntnarumit et al. showed that infants who do not respond to the initial course of treatment have persistently high NTpBNP levels compared to responders (2337 versus $353 \mathrm{pmol} / \mathrm{L}, P=.007$ ).

The ability of NTpBNP to predict the presence of a PDA seems to surpass that of BNP. There is a wide variation in BNP levels associated with a significant PDA ranging from $70-1110 \mathrm{pg} / \mathrm{mL}$ despite using the same assay [39-42]. This may be explained by the shorter half-life and instability of BNP described earlier. In addition, the correlation of NTpBNP with the echocardiographic markers of PDA significance is more consistent. Flynn et al. showed that BNP had a weaker correlation with echocardiographic markers of PDA significance including ductal size $(r=0.62)$, increased pulmonary flow $(r=0.63)$, and increased steal (retrograde diastolic flow) in the descending aorta (DAo) and the superior mesenteric artery (SMA) $(r=0.54$ and 0.41$)$. There was a poor correlation between left atrial to aortic ratio (LA : Ao ratio) and BNP levels $(r=0.33)$ in this study [43]. However, Choi BM et al. revealed a stronger correlation $(r=0.73)[39]$.

NTpBNP may be an ideal screening tool for a PDA due to relatively close cut-off levels of NTpBNP for diagnosis a PDA across the studies conducted thus far, the strong correlation with echo markers of PDA significance, and the lack of influence of antenatal and postnatal factors on the levels. In addition, the levels fall significantly following successful treatment and persist in nonresponders. This obviates the need for repeated echocardiograms to assess treatment success.

\section{NTpBNP and Outcome}

The ability of NTpBNP to predict short-term outcomes in preterm infants with a PDA was assessed by El-Khuffash et al. [29]. In the study described in the previous section, the PDA group was subdivided into infants with a poor outcome (grade III/IV IVH, death or both, $n=20$ ) and infants without complications $(n=25)$. The poor outcome group had a significantly lower gestation and birth weights. There were no differences in the antenatal characteristics between the two groups. Infants in the poor outcome group had a significantly higher NTpBNP levels at 48 hours compared to infants without PDA-associated complications (9284 pmol/L [5013-16 911] versus $5121 \mathrm{pmol} / \mathrm{L}$ [2324-6202], $P=.008)$. The AUC for NTpBNP's ability to predict severe IVH and/or death as a complication of a PDA is 0.84 (95\% CI $0.72-$ $0.96, P \leq .001)$. A level of $5500 \mathrm{pmol} / \mathrm{L}$ has a sensitivity of $80 \%$ and a specificity of $80 \%$. Only one infant in the Spontaneous PDA closure group died before discharge. The 12- and 48-hour NTpBNP levels were $2023 \mathrm{pmol} / \mathrm{L}$ and 6605 pmol/L respectively. NTpBNP may be an independent marker of poor neonatal short-term outcome irrespective of PDA presence (29).

Gagliardi L et al. assessed the discriminatory ability of the clinical risk index for babies (CRIBs), CRIB-II, and SNAPPEII in detecting death before discharge in 720 preterm infants
[44]. Following the exclusion of babies weighing 400-499 g ( $n=15)$, the AUCs for CRIB, CRIB-II, and SNAPPEII were $0.898,0.905$, and 0.835 , respectively. These results were comparable to the AUCs for NTpBNP and death in this cohort. NTpBNP may prove to be a useful adjunct to clinical and echocardiographic PDA staging system proposed by McNamara et al. [45]. Medical therapy for PDA has well recognised adverse effects and neither prophylaxis nor treatment on the basis of clinical and echocardiographic signs have been shown to improve long-term outcomes. Accurately identifying infants with PDA who are at highest risk of poor outcome using NTpBNP may allow more successful trials of targeted medical therapy of PDA.

\section{Other Applications of NTpBNP}

Pulmonary vascular resistance may remain elevated during the neonatal period leading to difficulties in oxygenation and resulting in pulmonary hypertension (PHT). Echocardiography is required to distinguish $\mathrm{PHT}$ from other respiratory and cardiac disorders by demonstrating suprasystemic pulmonary vascular pressures. In a study of 28 term infants, Baptista et al. showed a significantly higher NTpBNP level in infants with PHT secondary to congenital diaphragmatic hernia (CHD) compared to age and weight matched controls (1563 versus $591 \mathrm{pmol} / \mathrm{L}, P<.05)$. There was a good correlation with right ventricular mean pressure $(r=0.45$, $P=.03$ ) and RV Tei index. This measurement is a combined myocardial performance index (isovolumic contraction time plus isovolumic relaxation time divided by ejection time) $(r=-0.46, P=.02)$. In addition, the prognostic properties of NTpBNP are demonstrated in this trial. Nine infants in the CHD group died before discharge. NTpBNP was higher in the nonsurvivors (2679 versus $737 \mathrm{pmol} / \mathrm{L}, P=.009$ ). A level of $1360 \mathrm{pmol} / \mathrm{L}$ had a $100 \%$ sensitivity and $67 \%$ specificity for identifying these infants.

Plasma BNP increases in animal models with induced endotoxaemia and the proinflammatory cytokine inter leukin-6 (IL-6) has been linked with BNP production. Therefore, the rise of BNP may not be solely due to ventricular overloading. In neonatal rat cardiac myocytes, transcriptional activation of the BNP gene was initiated by lipopolysaccharide (LPS) suggesting that elevated BNP levels under endotoxaemic conditions are partially mediated by LPS [46]. In patients with severe sepsis or septic shock, BNP and NTpBNP values are highly elevated $[47,48]$ and, despite significant hemodynamic differences, comparable with those found in acute heart failure in adult patients. It remains to be determined how elevations of natriuretic peptide levels are linked to inflammation and sepsis-associated myocardial dysfunction [37, 48]. NTpBNP may also serve as useful laboratory marker to predict survival in patients presenting with severe sepsis [49]. Additionally, NTpBNP seems to be an early predictor of myocardial dysfunction in patients with septic shock [50]. NTpBNP may serve as a marker of cardiac dysfunction associated with sepsis in preterm neonates and be a useful adjunct in the diagnosis of sepsis. In preterm infants, NTpBNP rises in the presence of late onset sepsis 
without the presence of a PDA or ventricular dysfunction. The interpretation of NTpBNP levels in the presence of a PDA and sepsis warrants further study.

\section{Conclusion}

NTpBNP has a major diagnostic role in the adult population. In children, NTpBNP serves as an indicator of cardiac disease and may be used to monitor response to treatment. The potential benefit of these NTpBNP in neonatology is immense. It has a role in PDA screening, treatment response and may also offer prognostic information. More studies are needed to explore the possible roles of NTpBNP in the management of sepsis and monitoring of cardiac performance. These two possible confounding factors may limit its reliability in the diagnosis of PDA and its response to treatment.

\section{References}

[1] P. J. Hunt, T. G. Yandle, M. G. Nicholls, A. M. Richards, and E. A. Espiner, "The amino-terminal portion of Pro-brain natriuretic peptide (Pro-BNP) circulates in human plasma," Biochemical and Biophysical Research Communications, vol. 214, no. 3, pp. 1175-1183, 1995.

[2] T. Maack, "Receptors of atrial natriuretic factor," Annual Review of Physiology, vol. 54, pp. 11-27, 1992.

[3] R. Witthaut, "Science review: natriuretic peptides in critical illness," Critical Care, vol. 8, no. 5, pp. 342-349, 2004.

[4] Z. Abassi, T. Karram, S. Ellaham, J. Winaver, and A. Hoffman, "Implications of the natriuretic peptide system in the pathogenesis of heart failure: diagnostic and therapeutic importance," Pharmacology and Therapeutics, vol. 102, no. 3, pp. 223-241, 2004.

[5] T. Mueller, A. Gegenhuber, W. Poelz, and M. Haltmayer, "Diagnostic accuracy of B type natriuretic peptide and amino terminal proBNP in the emergency diagnosis of heart failure," Heart, vol. 91, no. 5, pp. 606-612, 2005.

[6] R. W. Troughton, C. M. Frampton, T. G. Yandle, E. A. Espiner, M. G. Nicholls, and A. M. Richards, "Treatment of heart failure guided by plasma aminoterminal brain natriuretic peptide (N-BNP) concentrations," The Lancet, vol. 355, no. 9210, pp. 1126-1130, 2000.

[7] M. M. Redfield, R. J. Rodeheffer, S. J. Jacobsen, D. W. Mahoney, K. R. Bailey, and J. C. Burnett Jr., "Plasma brain natriuretic peptide to detect preclinical ventricular systolic or diastolic dysfunction: a community-based study," Circulation, vol. 109, no. 25, pp. 3176-3181, 2004.

[8] I. S. Anand, L. D. Fisher, Y.-T. Chiang, et al., "Changes in brain natriuretic peptide and norepinephrine over time and mortality and morbidity in the Valsartan Heart Failure Trial (Val-HeFT)," Circulation, vol. 107, no. 9, pp. 1278-1283, 2003.

[9] A. Westerlind, H. Wahlander, G. Lindstedt, P.-A. Lundberg, and D. Holmgren, "Clinical signs of heart failure are associated with increased levels of natriuretic peptide types B and A in children with congenital heart defects or cardiomyopathy," Acta Paediatrica, vol. 93, no. 3, pp. 340-345, 2004.

[10] A. Nir, B. Bar-Oz, Z. Perles, R. Brooks, A. Korach, and A. J. Rein, "N-terminal pro-B-type natriuretic peptide: reference plasma levels from birth to adolescence. Elevated levels at birth and in infants and children with heart diseases," Acta Paediatrica, vol. 93, no. 5, pp. 603-607, 2004.
[11] A. Koch, S. Zink, and H. Singer, "B-type natriuretic peptide in paediatric patients with congenital heart disease," European Heart Journal, vol. 27, no. 7, pp. 861-866, 2006.

[12] N. Nasser, Z. Perles, A. J. Rein, and A. Nir, "NT-proBNP as a marker for persistent cardiac disease in children with history of dilated cardiomyopathy and myocarditis," Pediatric Cardiology, vol. 27, no. 1, pp. 87-90, 2006.

[13] S. Cohen, C. Springer, A. Avital, et al., "Amino-terminal pro-brain-type natriuretic peptide: heart or lung disease in pediatric respiratory distress?” Pediatrics, vol. 115, pp. 13471350, 2005.

[14] P. Gessler, W. Knirsch, B. Schmitt, V. Rousson, and A. von Eckardstein, "Prognostic value of plasma N-terminal probrain natriuretic peptide in children with congenital heart defects and open-heart surgery," Journal of Pediatrics, vol. 148, no. 3, pp. 372-376, 2006.

[15] F. Carmona, P. H. Manso, W. V. A. Vicente, M. Castro, and A. P. C. P. Carlotti, "Risk stratification in neonates and infants submitted to cardiac surgery with cardiopulmonary bypass: a multimarker approach combining inflammatory mediators, N-terminal pro-B-type natriuretic peptide and troponin I," Cytokine, vol. 42, no. 3, pp. 317-324, 2008.

[16] A. Shalev, A. Nir, and E. Granot, "Cardiac function in children post-orthotopic liver transplantation: echocardiographic parameters and biochemical markers of subclinical cardiovascular damage," Pediatric Transplantation, vol. 9, no. 6, pp. 718-722, 2005.

[17] C. G. Cowley, J. D. Bradley, and R. E. Shaddy, "B-type natriuretic peptide levels in congenital heart disease," Pediatric Cardiology, vol. 25, no. 4, pp. 336-340, 2004.

[18] M. Weber, R. Arnold, M. Rau, et al., "Relation of N-terminal pro B-type natriuretic peptide to progression of aortic valve disease," European Heart Journal, vol. 26, no. 10, pp. 10231030, 2005.

[19] W. E. Hopkins, Z. Chen, N. K. Fukagawa, C. Hall, H. J. Knot, and M. M. LeWinter, "Increased atrial and brain natriuretic peptides in adults with cyanotic congenital heart disease: enhanced understanding of the relationship between hypoxia and natriuretic peptide secretion," Circulation, vol. 109, no. 23, pp. 2872-2877, 2004.

[20] T. S. Mir, S. Marohn, S. Laer, M. Eiselt, O. Grollmus, and J. Weil, "Plasma concentrations of $\mathrm{N}$-terminal pro-brain natriuretic peptide in control children from the neonatal to adolescent period and in children with congestive heart failure," Pediatrics, vol. 110, no. 6, article e76, 2002.

[21] T. S. Mir, R. Laux, H. H. Hellwege, et al., "Plasma concentrations of aminoterminal pro atrial natriuretic peptide and aminoterminal pro brain natriuretic peptide in healthy neonates: marked and rapid increase after birth," Pediatrics, vol. 112, no. 4, pp. 896-899, 2003.

[22] A. Nir, A. Lindinger, M. Rauh, et al., "NT-pro-B-type natriuretic peptide in infants and children: reference values based on combined data from four studies," Pediatric Cardiology, vol. 30, no. 1, pp. 3-8, 2009.

[23] B. Bar-Oz, A. Lev-Sagie, I. Arad, L. Salpeter, and A. Nir, "N-termonal pro-B-type natriuretic paptide concentrations in mothers just before delivery, in cord blood, and in newborns," Clinical Chemistry, vol. 51, no. 5, pp. 926-927, 2005.

[24] A. El-Khuffash and E. J. Molloy, "Are B-type natriuretic peptide (BNP) and N-terminal-pro-BNP useful in neonates?" Archives of Disease in Childhood: Fetal and Neonatal Edition, vol. 92, pp. F320-F324, 2007.

[25] A. EL-Khuffash, P. G. Davis, K. Walsh, and E. J. Molloy, "Cardiac troponin $\mathrm{T}$ and $\mathrm{N}$-terminal-pro-B type natriuretic 
peptide reflect myocardial function in preterm infants," Journal of Perinatology, vol. 28, no. 7, pp. 482-486, 2008.

[26] W. F. Friedman and S. E. Kirkpatrick, "In situ physiological study of the developing heart," Recent Advances in Studies on Cardiac Structure and Metabolism, vol. 5, pp. 497-504, 1975.

[27] S. Noori and I. Seri, "Pathophysiology of newborn hypotension outside the transitional period," Early Human Development, vol. 81, no. 5, pp. 399-404, 2005.

[28] A. El-Khuffash, M. Higgins, K. Walsh, and E. J. Molloy, "Quantitative assessment of the degree of ductal steal using celiac artery blood flow to left ventricular output ratio in preterm infants," Neonatology, vol. 93, no. 3, pp. 206-212, 2008.

[29] A. El-Khuffash, D. Barry, K. Walsh, P. G. Davis, and E. J. Molloy, "Biochemical markers may identify preterm infants with a patent ductus arteriosus at high risk of death or severe intraventricular haemorrhage," Archives of Disease in Childhood: Fetal and Neonatal Edition, vol. 93, no. 6, pp. f407f412, 2008.

[30] L. Schwachtgen, M. Herrmann, T. Georg, P. Schwarz, N. Marx, and A. Lindinger, "Reference values of NT-proBNP serum concentrations in the umbilical cord blood and in healthy neonates and children," Zeitschrift fur Kardiologie, vol. 94, no. 6, pp. 399-404, 2005.

[31] A. Hammerer-Lercher, E. Neubauer, S. Muller, O. Pachinger, B. Puschendorf, and J. Mair, "Head-to-head comparison of N-terminal pro-brain natriuretic peptide, brain natriuretic peptide and N-terminal pro-atrial natriuretic peptide in diagnosing left ventricular dysfunction," Clinica Chimica Acta, vol. 310, no. 2, pp. 193-197, 2001.

[32] J. Bakker, I. Gies, B. Slavenburg, O. Bekers, T. Delhaas, and M. van Dieijen-Visser, "Reference values for N-terminal proB-type natriuretic peptide in umbilical cord blood," Clinical Chemistry, vol. 50, no. 12, p. 2465, 2004.

[33] M. Rauh and A. Koch, "Plasma N-terminal pro-B-type natriuretic peptide concentrations in a control population of infants and children," Clinical Chemistry, vol. 49, no. 9, pp. 1563-1564, 2003.

[34] S. J. Soldin, O. P. Soldin, A. J. Boyajian, and M. S. Taskier, "Pediatric brain natriuretic peptide and N-terminal pro-brain natriuretic peptide reference intervals," Clinica Chimica Acta, vol. 366, no. 1-2, pp. 304-308, 2006.

[35] A. F. El-Khuffash, M. Amoruso, M. Culliton, and E. J. Molloy, "N-terminal pro-B-type natriuretic peptide as a marker of ductal haemodynamic significance in preterm infants: a prospective observational study," Archives of Disease in Childhood: Fetal and Neonatal Edition, vol. 92, no. 5, pp. F421F422, 2007.

[36] P. Nuntnarumit, A. Khositseth, and P. Thanomsingh, "Nterminal probrain natriuretic peptide and patent ductus arteriosus in preterm infants," Journal of Perinatology, vol. 29, no. 2, pp. 137-142, 2009.

[37] I. Farombi-Oghuvbu, T. Matthews, P. D. Mayne, H. Guerin, and J. D. Corcoran, "N-terminal pro-B-type natriuretic peptide: a measure of significant patent ductus arteriosus," Archives of Disease in Childhood: Fetal and Neonatal Edition, vol. 93, no. 4, pp. F257-F260, 2008.

[38] S. Ramakrishnan, Y. M. Heung, J. Round, T. P. Morris, P. Collinson, and A. F. Williams, "Early N-terminal pro-brain natriuretic peptide measurements predict clinically significant ductus arteriosus in preterm infants," Acta Paediatrica, vol. 98, no. 8, pp. 1254-1259, 2009.

[39] B. M. Choi, K. H. Lee, B. L. Eun, et al., "Utility of rapid B-type natriuretic peptide assay for diagnosis of symptomatic patent ductus arteriosus in preterm infants," Pediatrics, vol. 115, pp. e255-e261, 2005.

[40] H. Holmstrom, C. Hall, and E. Thaulow, "Plasma levels of natriuretic peptides and hemodynamic assessment of patent ductus arteriosus in preterm infants," Acta Paediatrica, vol. 90, no. 2, pp. 184-191, 2001.

[41] H. Holmstrom and T. Omland, "Natriuretic peptides as markers of patent ductus arteriosus in preterm infants," Clinical Science, vol. 103, no. 1, pp. 79-80, 2002.

[42] S. Sanjeev, M. Pettersen, J. Lua, R. Thomas, S. Shankaran, and T. L'Ecuyer, "Role of plasma B-type natriuretic peptide in screening for hemodynamically significant patent ductus arteriosus in preterm neonates," Journal of Perinatology, vol. 25, no. 11, pp. 709-713, 2005.

[43] P. A. Flynn, R. L. Da Graca, P. A. M. Auld, M. Nesin, and C. S. Kleinman, "The use of a bedside assay for plasma Btype natriuretic peptide as a biomarker in the management of patent ductus arteriosus in premature neonates," Journal of Pediatrics, vol. 147, no. 1, pp. 38-42, 2005.

[44] L. Gagliardi, A. Cavazza, A. Brunelli, et al., "Assessing mortality risk in very low birthweight infants: a comparison of CRIB, CRIB-II, and SNAPPE-II," Archives of Disease in Childhood: Fetal and Neonatal Edition, vol. 89, no. 5, pp. F419F422, 2004.

[45] P. J. McNamara and A. Sehgal, "Towards rational management of the patent ductus arteriosus: the need for disease staging," Archives of Disease in Childhood: Fetal and Neonatal Edition, vol. 92, no. 6, pp. F424-F427, 2007.

[46] K.-I. Tomaru, M. Arai, T. Yokoyama, et al., "Transcriptional activation of the BNP gene by lipopolysaccharide is mediated through GATA elements in neonatal rat cardiac myocytes," Journal of Molecular and Cellular Cardiology, vol. 34, no. 6, pp. 649-659, 2002.

[47] R. Witthaut, C. Busch, P. Fraunberger, et al., "Plasma atrial natriuretic peptide and brain natriuretic peptide are increased in septic shock: impact of interleukin-6 and sepsis-associated left ventricular dysfunction," Intensive Care Medicine, vol. 29, no. 10, pp. 1696-1702, 2003.

[48] A. Rudiger, S. Gasser, M. Fischler, T. Hornemann, A. Von Eckardstein, and M. Maggiorini, "Comparable increase of B-type natriuretic peptide and amino-terminal pro-B-type natriuretic peptide levels in patients with severe sepsis, septic shock, and acute heart failure," Critical Care Medicine, vol. 34, no. 8, pp. 2140-2144, 2006.

[49] M. Brueckmann, G. Huhle, S. Lang, et al., "Prognostic value of plasma N-terminal pro-brain natriuretic peptide in patients with severe sepsis," Circulation, vol. 112, no. 4, pp. 527-534, 2005.

[50] A. Roch, J. Allardet-Servent, P. Michelet, et al., "NH2 terminal pro-brain natriuretic peptide plasma level as an early marker of prognosis and cardiac dysfunction in septic shock patients," Critical Care Medicine, vol. 33, no. 5, pp. 1001-1007, 2005. 


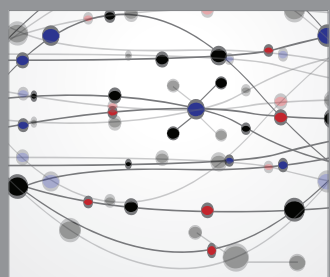

The Scientific World Journal
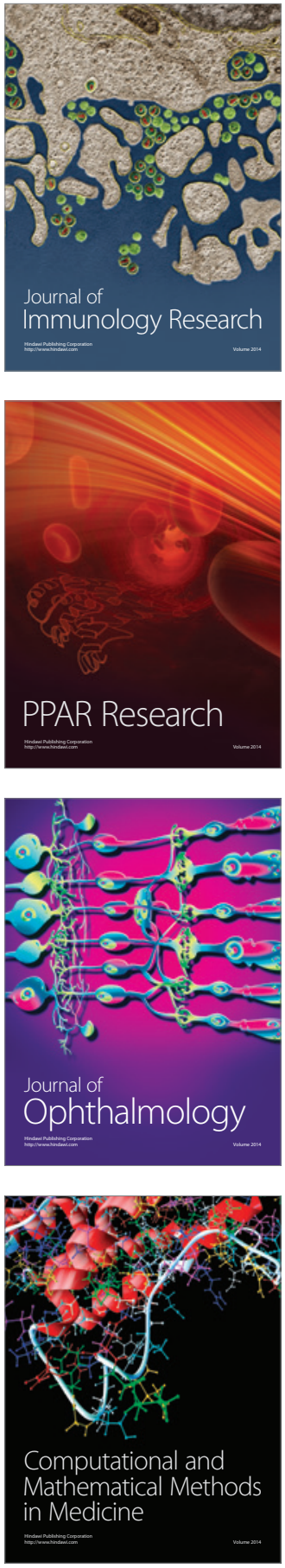

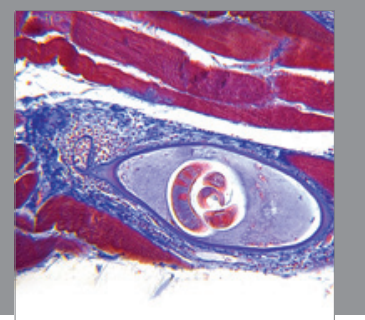

Gastroenterology

Research and Practice
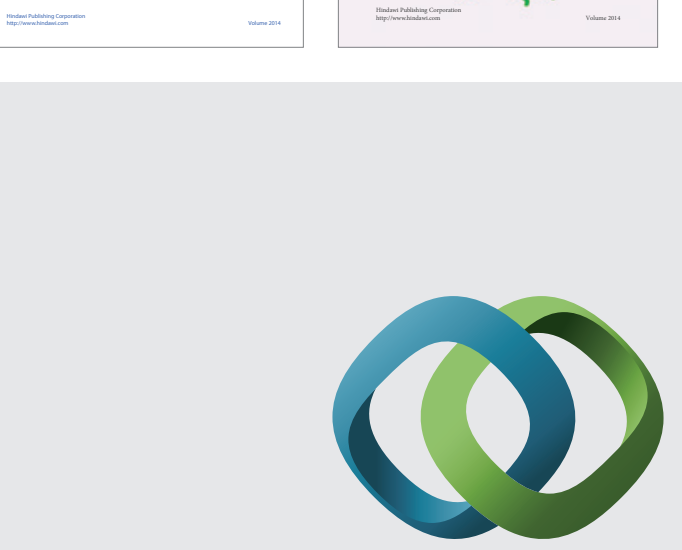

\section{Hindawi}

Submit your manuscripts at

http://www.hindawi.com
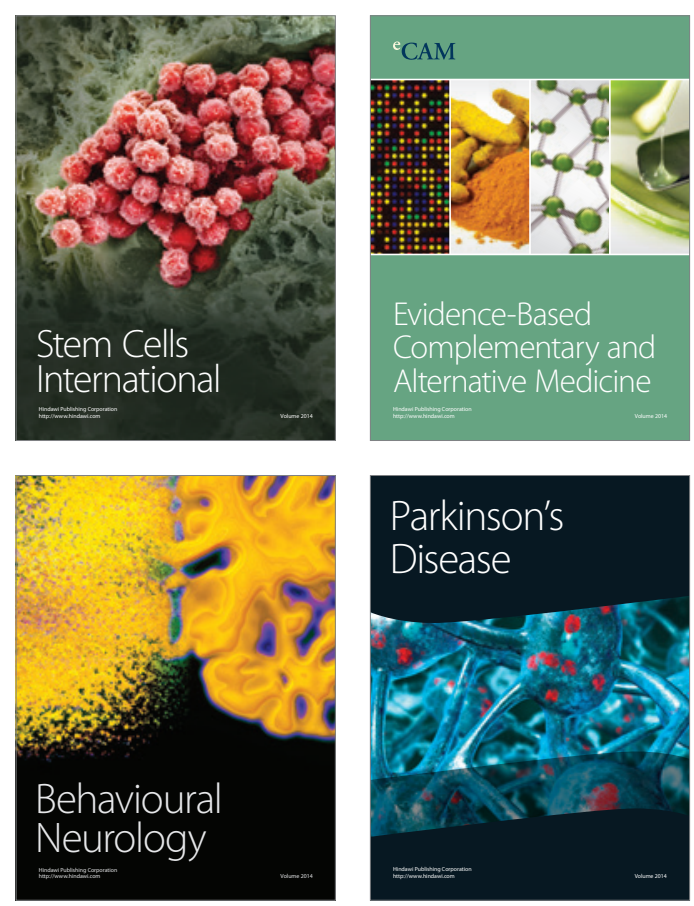

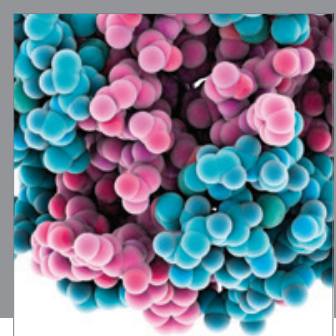

Journal of
Diabetes Research

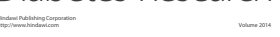

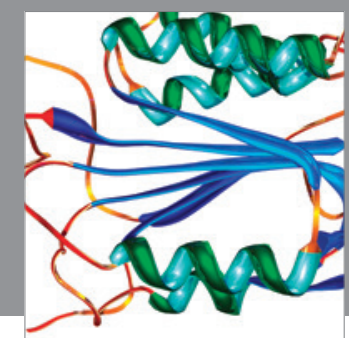

Disease Markers
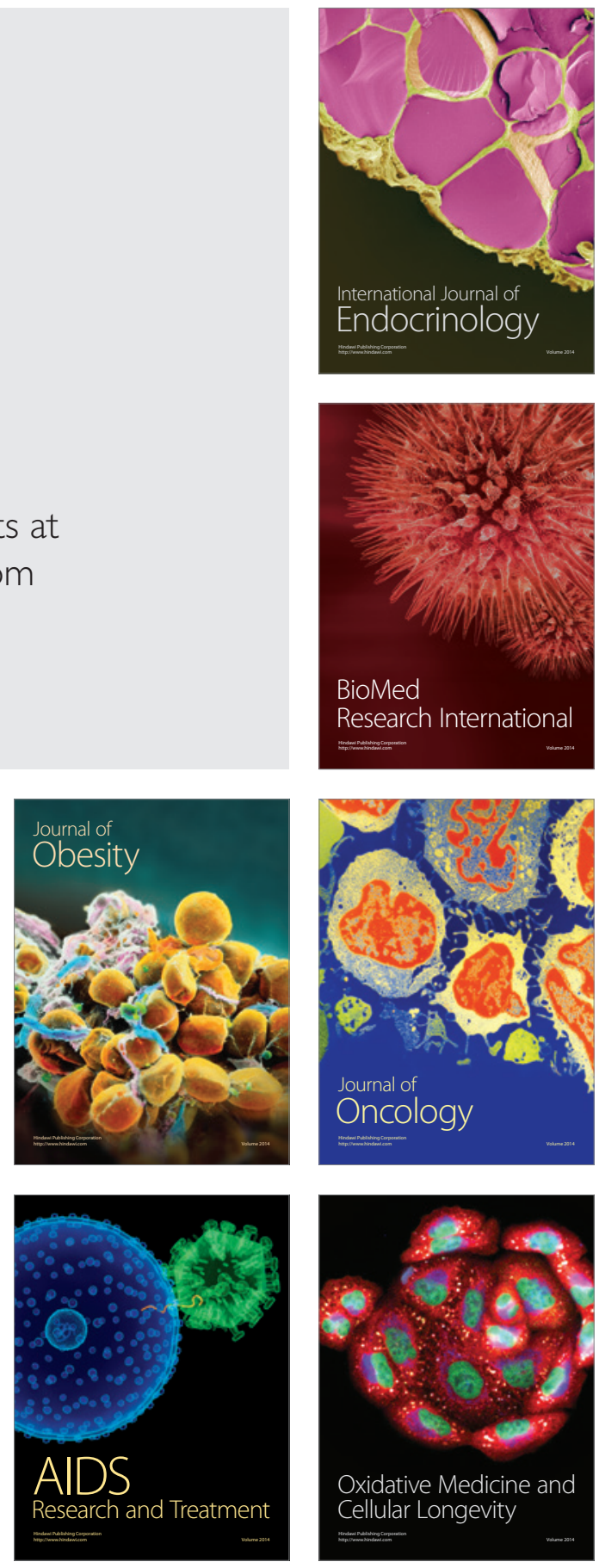